\title{
Los juegos y los contextos
de los preadolescentes
}

Milagros Damián Díaz

\section{Resumen}

El objetivo de este artículo es identificar y analizar las elecciones de juego en diferentes contextos: escuela, barrio o casa, y el favorito de preadolescentes de los grados cuarto, quinto y sexto de primaria tanto de escuelas oficiales como de privadas, con el fin de usar esa información como recurso pedagógico y contribuir al sistema de enseñanza-aprendizaje de los educandos.

Palabras claves: juegos; contextos; colegio; barrio; favorito; preadolescentes.

\section{Introducción}

Para abordar el tema de las elecciones de juego, es necesario conocer de qué manera el preadolescente comienza a utilizar su tiempo libre. Al respecto, García (2000) afirma que el tiempo libre surge como oposición al tiempo de trabajo. Es un tiempo susceptible de ser calculado con un reloj o con un calendario, fuera del trabajo y las obligaciones. Diversos autores se 
han ocupado de las características del juego y de conferirle a éste una definición acorde con los resultados de sus estudios y descubrimientos.

Por otra parte, Decroly y Manchamp (1914, citados por Omeñaca y Ruíz, 2004) destacan en la actividad lúdica el placer y la alegría que le son inherentes y el hecho de no implicar un fin consciente al margen de la propia acción del juego. Mientras que Buytendij (1933, citado en Omeñaca y Ruíz, 2004) resalta también algunos retos como elementos distintivos: la alegría, la espontaneidad y el esparcimiento. Por su parte, Huizinga (1972, citado en Omeñaca y Ruíz, 2004) en su tratado de Homo Ludens ahonda en alguna de las ideas anteriores y aporta otras nuevas al considerar que el juego constituye una actividad libre, produce satisfacción y alegría, representa una actuación llena de sentido, transcurre dentro de sí mismo, está lleno de armonía y crea orden.

Por otro lado, es ya conocida la importancia del juego en la influencia y la relación directa con el desarrollo psicológico y en el aprendizaje, en los aspectos emocionales y sociales. También, fomenta el desarrollo de la creatividad ya que puede ser un valioso recurso pedagógico (Delval, 1994) y una técnica terapéutica en la psicoterapia infantil (Hugges, 1994), sólo por mencionar algunas funciones.

Los niños van construyendo un mundo lógico a través de aspectos relacionados con el entorno, principalmente con aquellas actividades de la vida adulta; para ello, en los juegos deben estar presentes nuevas formas de organización del pensamiento, que es donde encuentra su lugar en el juego infantil, y que ha sido descrito por Piaget (1986) como la actividad recreativa principal del ser civilizado que abarca desde el juego sensoriomotor, el juego simbólico y el juego de reglas. $\mathrm{Y}$ al tratarse de cualesquiera de los tipos de juegos, éstos muestran dos características: involucran la competencia entre dos o más jugadores y están regidos por un conjunto de reglas aceptadas con anticipación por todos los jugadores y que no se pueden modificar durante el transcurso del juego; dichas reglas pueden ya estar establecidas en el juego o los jugadores pueden ponerse de acuerdo para seguirlas en el momento (Hugges, 2006). 
El mundo exterior del niño varía entre personas y objetos reconocidos que serán parte de los juegos infantiles, y de esta manera surgirán diferentes tipos de juegos, como los que tienen una marca social formalizada y que están más sujetos a reglas y normas; hay que tener presente que el juego es constructivo y que pertenece al área social, apoya la comprensión del exterior y permite hacer relaciones interpersonales. Será entonces cuando los diversos tipos de juegos practicados se irán consolidando en el desarrollo normal del niño hasta institucionalizarse, y que tendrán reglas para, posteriormente, formar parte de la cultura (Barrós, 2005).

Por otra parte, Garzarelli (2005) asegura que se pueden diferenciar fundamentalmente dos modelos de juego: un modelo competitivo y un modelo participativo. El competitivo se asocia a exigencia, niveles variables de estrés y situaciones de éxito o fracaso. El modelo participativo se relaciona más con aspectos lúdicos, relajantes y socializadores. Ambos modelos tienden a adecuarse a las exigencias y resultados del desarrollo psicológico del niño pre o adolescente.

Al respecto, Berg (2009) describe las etapas del juego y de la identidad desde los primeros meses hasta la madurez:

a. Etapa amorfa: Es aquella durante la cual el niño comienza a crear y formar una identidad al asumir las formas más simples de juego de rol. En esta etapa el niño ha aprendido un conocimiento social fundamental sobre el mundo humano $y$, además, se ha divertido. Ha aprendido a experimentar, aunque de una manera desarticulada e inconsciente, de que él mismo es un participante en la sociedad en la que existen reglas sociales que proporcionan orden a la vida, junto con fuerzas biológicas y experiencias emocionales fundamentales de unión y separación. Cuando surge la imitación sistemática es cuando el niño empieza a crear un orden desde un punto de vista subjetivo que cumple con las normas que le indican las otras personas; esto revela también que el niño es capaz de incorporar distintas formas del mundo exterior a su propio comportamiento, lo que le permitirá desarrollar distintas identidades. Por lo tanto, la lógica implícita de la etapa 
amorfa sería que no existe todavía una capacidad para diferenciar las formas, las identidades. Esta capacidad empieza a ejercitarse mediante la mímica y la imitación-repetición del niño.

b. Juego espontáneo: Consiste en que el niño descubre que no basta con ser un jugador o participante indiferenciado, sino que es posible y adecuado ser un tipo especial de participante. Puede identificarse a sí mismo como un niño o una niña, o un adulto. Tiene lugar el juego de identidades, que corresponde con el desarrollo lingüístico y que empieza cuando el niño toma conciencia de las palabras. El niño destina una cantidad considerable de energía emocional para identificarse como caballero, princesa, soldado o pirata, bruja o hada, lo que significa el deseo de crecer emocional y cognoscitivamente, probando las posibilidades y la confianza en esta interpretación de roles, con lo cual se desarrolla una capacidad dramática y una empatía muy fuertes que moldean y crean las emociones sociales básicas humanas.

Los niños asimilan importantes experiencias humanas de fuerza-debilidad, lo bueno-lo malo, lo bonito-lo feo; por otra parte, el niño tendrá dificultades para desarrollarse moralmente si reprime sus conflictos humanos fundamentales en el mundo del juego de roles, puesto que la expresión de los gestos y las actitudes revelan la emoción o el sentimiento que expresan. Esta etapa finaliza cuando el juego de los niños está lleno de esta expresividad autogenerada, lo que, además, les proporciona un entrenamiento para la empatía.

c. Juego organizado: De éste, Berg describe su sentido: se da cuando el niño es capaz de asumir una identidad e imaginar al mismo tiempo los roles de los demás jugadores, adaptándose a ellos, lo que quiere decir que el niño asume explícitamente un rol, mientras que los roles de los demás participantes están claros para él o ella de forma implícita. Cuando todos los participantes logran esto, se obtiene una adaptación y comprensión mutuas de las identidades co- 
rrespondientes, y así la identidad del niño existe en relación con la multitud de identidades del escenario social. En esta etapa del juego organizado, el niño ha alcanzado la capacidad de atender un único rol en la esfera social y a tomar parte de forma constructiva en el juego desde ese único rol, la base de su individualidad e identificación de su mundo interno emocional. La etapa del juego organizado se conoce como el periodo de la vida en el que se aprende, también ser sujeto social responsable, la destreza de controlar su propia posición o rol en una interacción social y la aceptación de las emociones que despierta esa interacción.

d. Generalización y la madurez: Consiste en que los seres humanos poseen una constelación única y muy especial de distintas identidades y roles, es decir, es una etapa de conclusión del desarrollo psíquico de la identidad y el reconocimiento de las emociones propias y de los demás, de esta forma se dice que el individuo combina todos los roles en los que ha participado. Berg (2009) alude que sin el juego de roles y la participación en los juegos, no habría un desarrollo de la personalidad.

Las etapas del juego y de la identidad de Berg (2009) en conjunto con el desarrollo cognoscitivo a través de sus etapas y las del juego, son algunas posturas teóricas importantes para dar cuenta de por qué juegan y qué juegan los preadolescentes.

De esta manera, el tipo de pensamiento y del juego corresponden a etapas del sensoriomotor o juego sensoriomotor $\mathrm{y}$, al igual que el juego simbólico y el reglado, corresponden a los estadios del pensamiento sensoriomotor, preoperatorio, concreto y del pensamiento formal. Por lo tanto, se precisa revisar brevemente las características de estas etapas del desarrollo cognoscitivo tomando en cuenta que no se pueden separar éste desarrollo y el afectivo (Piaget, 1992).

Piaget menciona que los niños en la etapa de las operaciones concretas (7 a los 11 años aproximadamente) comienzan rápidamente a hacer operaciones cognoscitivas, las cuales permiten a los niños modificar y reorganizar sus imágenes y símbolos 
para llegar a una conclusión lógica. En esta etapa los niños logran una mejor comprensión de las relaciones cuantitativas y lógicas y son capaces de elaborar una seriación mental, y sus capacidades operacionales evolucionan gradual y secuencialmente. Los niños operacionales concretos pueden llegar a una conclusión correcta si se les proporcionar una evidencia con hechos concretos.

También, Piaget (1992) describe que en esta etapa los juegos tienen un carácter más directivo, tienen una marca social formalizada y están más sujetos a reglas y normas. El juego es constructivo en el área social y se denomina juego de reglas, este tipo de juego forma parte del crecimiento emocional de los menores, junto con otros, como el juego de imitación, personajes o ficción, el juego de azar, el juego estructurado y el juego libre (Navarro, 2002).

Con respecto a la etapa de las operaciones formales, que se observa en las edades de 11 o 12 años en adelante, su punto de referencia es que pueden generar hipótesis, es decir, en este momento es más importante para las personas pensar en lo que es posible y no en lo que es real. También piensan en forma inductiva, esto es un tipo de pensamiento que exhiben los científicos, que generan hipótesis y después las prueban sistemáticamente a través de experimentos. El pensamiento operacional formal es racional, sistemático y abstracto, por lo que el niño adolescente puede pensar de manera planeada, utilizar ideas y conceptos hipotéticos, incluso sobre aquellos que contradicen la realidad. Estos avances del desarrollo cognoscitivo ayudan a las personas a generar varias alternativas para resolver un problema y responder preguntas para encontrar sentido a hechos de la vida, la religión y la justicia (Piaget, citado por Delval, 1994).

Ahora, con base en lo anterior, se retoma el objetivo de este trabajo que es identificar, describir y analizar la elección de los juegos en los distintos contextos: los juegos que practican en el colegio, en casa o barrio, los juegos favoritos de niños y niñas de cuarto, quinto y sexto de primaria, con el fin de obtener información relevante para fundamentar la importancia y la utilidad psicopedagógica del juego en los preadolescentes. 


\section{Método}

Sujetos: 2,978 niños (1,493 niños y 1,485 niñas) de edades comprendidas entre los 8 a 15 años, de grado escolar cuarto, quinto y sexto de primaria, tanto de escuelas privadas como oficiales. La muestra es no aleatoria, y se aplicó a voluntarios del Estado de México y de Ciudad de México.

Aparatos y materiales: cuestionarios impresos, computadora, grabadora, mesas y sillas, lápices y colores.

Variables atributivas: sexo, grados, escolares, escuelas oficiales y privadas.

Variables dependientes: los juegos que se practican en la escuela, en el barrio, en la casa y el juego favorito.

Es un estudio cuantitativo y exploratorio que tiene el propósito de indagar lugares, contextos o escenarios donde se practican ciertos juegos y preferencias de los niños y niñas preadolescentes de escuelas oficiales y privadas.

\section{Procedimiento}

Primera fase: aplicación del cuestionario que contempla los siguientes datos personales: fecha de nacimiento, edad, sexo, escuela, curso o grado, hermanos mayores y menores. $Y$ las siguientes preguntas abiertas: ¿a qué juegas con tus amigos en la escuela y en el barrio o en tu casa?, ¿cuál es el juego que más te gusta y cómo se juega?

El aplicador les leyó cada una de las preguntas que se contemplan en el cuestionario y se cercioró de que los niños entendieran cada una de ellas. La muestra es no aleatoria, que se aplicó a voluntarios de escuelas públicas y privadas del Estado de México y de Ciudad de México.

Segunda fase: Se organizó la información en función de las variables estudiadas. 
Tercera fase: Se identificó y se recabó la información bruta (los juegos) de cada contexto (colegio, barrio o casa, y el favorito).

\section{Resultados}

A continuación se describen los datos más sobresalientes encontrados en este estudio, que consistió en enfocarse en niños y niñas de cuarto, quinto y sexto de primaria, en relación con las variables atributivas que son sexo y grados escolares; de los tipos de escuela oficial y privada; y a las variables dependientes como los diferentes contextos que se abordan: colegio, barrio o casa y el juego favorito.

Como se puede observar, en la Figura 1 se representa el futbol de niños y niñas en todos los contextos, y es notorio la diferencia de los niños que sobrepasan a las niñas. Las puntuaciones de los niños en el futbol fueron: en el colegio 827, en el barrio 884 y el favorito 827. En cambio, el de las niñas varía entre muñecas, atrapadas y escondidas en los grados señalados. Y las escuelas públicas acaparan la mayor cantidad de niños que juegan futbol.

Por otra parte, en la Figura 2 se observa niños y niñas en los contextos y los tres grados. La mayor cantidad de niños que juegan futbol es de sexto grado, en el barrio o casa (265 niños). En tanto, las niñas de quinto grado juegan con mayor frecuencia a las atrapadas, en el colegio (116). El juego favorito con más altos puntajes son el de las niñas de cuarto grado que juegan escondidas (69).

El futbol es el juego más practicado por los niños de escuelas públicas (579), no obstante, la diferencia es poca entre los niños (431) de escuela privada.

En el último contexto, juego favorito, los datos indican que los niños prefieren el futbol y conforme avanzan en los grados se incrementa la frecuencia de niños que lo juegan. Mientras tanto, las niñas prefieren el juego de las escondidas. 


\section{Conclusiones}

Los juegos pueden diferir por los contextos o situaciones donde se practican, también por el hecho de ser niño o niña, o por razones propias del desarrollo psicológico. Por ejemplo, en el contexto del colegio se propician más juegos grupales por la cantidad de niños. En el contexto de casa o barrio, en especial, las niñas juegan a las muñecas o a representar roles como de la maestra, de la novia, etcétera. $Y$ en cuanto al juego favorito, coincide con la alta frecuencia de juegos que los niños prefieren en los anteriores contextos.

A pesar de que los adolescentes pueden ser creativos para formular sus propios juegos con sus propias reglas, los juegos más aceptados son los que ya tienen reglas formuladas y pueden ser acordadas por ellos y por los adultos. Los juegos con reglas toman muchas formas, una de ellas, que se observa durante la infancia, es la actividad física extremadamente organizada.

Ahora, el conocimiento de las etapas del desarrollo cognoscitivo, afectivo y social de los niños podría ser un referente para saber qué juegos y qué juguetes eligen y utilizan con mayor frecuencia a lo largo del desarrollo. Por ejemplo, aproximadamente entre los 6 y 8 años de edad, los niños eligen juegos como el uso de cuerdas, pelotas, patines, coches, bicicletas, lupas, imanes, la lotería, lo que les permite sentirse seguros o inseguros, competentes o inhábiles frente a los demás.

Por otra parte, disminuye la importancia del juego simbólico y se interesan por juegos de reglas que son los que tienen una serie de instrucciones o normas que los jugadores deben conocer y respetar para conseguir resultados. Buscan juegos de mesa o de tablero, de puntería, de cestas, futbolines, entre otros. Estos juegos reglados son fundamentales con relación a que funcionan como elementos socializadores porque enseñan a los niños a ganar y a perder, a respetar turnos, normas y las acciones de los compañeros de juego; favoreciendo así el desarrollo social y emocional

Más delante, entre los 9 y 12 años de edad, los niños se interesan por actividades de equipo, deportivas e intelectuales, patines, mecanos, juegos de estrategia y reflexión, maquetas, 
colecciones de todo tipo, juegos de mesa, audiovisuales, electrónicos y para realizar experimentos. Estos juegos les permite la expresión de ternura, cariño, desconfianza o confianza, competencia y rivalidad o compañía y cooperación. Posteriormente, jugar con juguetes es menos frecuente, comienzan a entrar en la adolescencia y van construyendo su propia identidad, por eso se promueven a través del lenguaje, de la memoria, del razonamiento, de la atención y de la reflexión (Navarro, 2002).

También, tienen aficiones personales por las diferentes formas de ocio y sus intereses se dirigen a libros, música y videojuegos. No obstante, se debe tener en cuenta el tiempo diario de juego y cuidar los contenidos, para que no se priven de otras experiencias importantes ya que van conformando el autoconcepto, la autovaloración y la relación con sus iguales, dentro de un marco de intimidad y lejanía, de expresión clara y abierta de sus emociones o la limitación, aislamiento y hermetismo de sus sentimientos reales (Monk, 2005).

La evidencia de los juegos descritos anteriormente hace patente el hecho de que el juego forma parte del desarrollo integral del niño y preadolescente, logrando con ello que las emociones sean conocidas, reconocidas, expresadas y canalizadas. También se va manifestando la elección que van haciendo de los juegos, es decir, a la par de su desarrollo psicomotor, intelectual y conductual, los niños van desarrollando el manejo de las emociones, la autorregulación de éstas, la socialización y la internalización de la cultura (Berg, 2009).

A partir de ello, en este estudio se observó que los resultados presentan reiteradamente el futbol como el juego más practicado por los niños en los tres contextos, sin embargo, en los contextos barrio y favorito se alcanzan los puntajes más altos, y en sexto grado de primaria es donde se presentan las frecuencias más altas. Y con respecto a las niñas, lo que más juegan a atrapadas en los colegios públicos y a las escondidas en el barrio y como juego favorito, además, son las niñas más pequeñas las que juegan atrapadas y escondidas. Estos juegos tienen una razón evolutiva muy poderosa ya que son sensoriomotores primordialmente, y se caracterizan por el continuo ejercicio y el placer sensorial de correr. 
Ahora, en relación con el futbol, este es un juego más estructurado y reglado, y es practicado principalmente por los varones, esto se debe posiblemente a la fama inmersa en un aparato impresionante de publicidad o quizás por la cantidad de los ídolos mexicanos que sobresalen en el extranjero en este deporte y que ganan mucho dinero en poco tiempo, que es lo que atrapa una gran cantidad de espectadores y seguidores.

Al respecto, Angelotti (2005) asegura que el futbol es el deporte más popular en México no sólo por sus propiedades que superan los límites económicos y sociales en este país, sino porque se ha convertido en un negocio para mucha gente, un motivo de celebración, un espectáculo y una fuente de emoción muy fuerte en los aficionados, esto debido también, tal vez, a la gran variedad de clubes de futbol existentes, por lo que cada aficionado tiene la opción de elegir entre la llamada comúnmente "pasión" por un equipo o por el estado de la república en el que se encuentre viviendo. En la actualidad, los chicos buscan divertirse con alguna actividad que sea de interés y común para la mayoría de los integrantes de un grupo, ya sea grande o pequeño. El futbol es un juego que al conferirle nuevas reglas, éstas son adaptadas a su entorno para que se practique casi en cualquier lugar, incluso en la calle.

El futbol ha sido motivo de estudio debido a su amplia aceptación por parte de diversas culturas. Por ejemplo, en Sudamérica se ha adoptado como un deporte primordial y esencial para la sociedad de cada país. Santa Cruz (1998) menciona que la importancia del futbol radica en la identificación de las personas con el ídolo nacional visto como un héroe por otros fanáticos. El héroe representa el ideal de algún individuo común que quisiera llegar a producir dichos logros y hazañas. En este sentido, es muy común ver a los adolescentes en la búsqueda de identidad, ya que comienzan a crear una copia de sus ídolos. Cada persona admira a alguien destacado en el mundo deportivo, por lo que en ocasiones el adolescente tratará de imitar sus habilidades para demostrar su admiración. Asimismo, se pueden ver a muchos chicos practicar movimientos o trucos con el balón hechos por deportistas famosos, incluso, copian su corte de cabello. 
Hurlock (2000) asevera que los varones descubren que los atletas sobresalen como los héroes de la escuela. En tanto que las chicas descubren que ser una atleta destacada acarrea escaso prestigio entre sus allegados. Padres, profesores, miembros de la comunidad refuerzan el prestigio del futbol en ocasiones, pero restan importancia al rendimiento escolar. Los varones que carecen de desarrollo físico o de capacidad para convertirse en participantes activos, muestran su interés hablando de futbol y manteniéndose al tanto de los sucesos futbolísticos a través de los periódicos, de la radio y la televisión.

Cachorro (2001) llevó a cabo un estudio en la Ciudad de México, en una calle con una cancha de futbol improvisada y con participantes que se encuentran en la vida cotidiana. Aseguró que el futbol es tan popular que los practicantes buscarán el medio para practicarlo, aunque no se cuente con los espacios suficientes para hacerlo. Por otra lado, Pérez (2006) afirma que el impacto que tiene el futbol en México se extiende directamente sobre las personas que disfrutan de este espectáculo haciéndolos participantes indirectos. Y enfatiza que al ser tan popular este deporte, grandes empresas buscan formar parte del espectáculo para hacerlo cada vez más llamativo. Es así como los jóvenes, a muy temprana edad, comienzan a practicar el futbol por imitación de las grandes figuras de este deporte.

\section{Referencias}

Angelotti, P. G. H. (2005). La dinámica del futbol en México. La construcción de identidades colectivas en torno al club de futbol Pachuca en nuestros días. Revista Digital Efe Deportes, 82.

Barrós, R. (2005). ¿De dónde viene y hacia dónde va la psicología del deporte en el siglo XXI? Revista Digital-Buenos Aires, 10(87). Recuperado de http://www.efdeportes.com/

Berg, L. E. (2009). Etapas de desarrollo del juego en la construcción de la identidad infantil: una contribución teórica interaccionista. El juego y el desarrollo emocional. Universidad de Göteborg, Suecia. 
Cachorro, G. M. (2001). El futbol y los chavos banda. Primera parte: Una investigación etnográfica del deporte, en una plaza del D.F. de México. Revista Digital-Buenos Aires, 7(37). Recuperado de http://www.efdeportes.com/

Delval, J. (1994). El desarrollo humano. España: Siglo XXI Editores. Recuperado de http://www.efdeportes.com/

Garzarelli, J. C. (2005). El juego, soporte del deporte. Parte I. Revista Electrónica. Psicología del Deporte. Buenos Aires. Recuperado de http://www.efdeportes.com/

Hugges, F. P. (2006). El juego, su importancia en el desarrollo psicológico del niño y del adolescente. México: Editorial Trillas.

Hurlock, E. B. (2000). Psicología de la adolescencia. México: Paidós. Mook, B. (2005). Terapia de juego fenomenológica. En CH.E. Schaefer (eds.). Fundamentos de terapia de juego. México: Editorial Manual Moderno.

Navarro, A.V. (2002). El afán de jugar. Teoría y práctica de los juegos motores. México: Editorial Manual Moderno.

Omeñaca, C. R. y Ruíz, O. J. V. (2004). Juegos cooperativos y Educación física, México: Editorial Paidotribo.

Pérez, B. F. (2006). Aproximación inicial al deporte del futbol. México: Trillas.

Piaget, J. (1986). La formación del símbolo en el niño. México: Fondo de Cultura Económica. tini.

. (1986). Psicología y pedagogía del juego. Barcelona: Agos-

Santa Cruz, A. E. (1998). ¿Hacia dónde va nuestro futbol? Nueva Sociedad, 154. Revista Digital-Buenos Aires, 7(37): 157-167. 